\title{
Abstracts of Award-Winning Posters 8th Annual Health Sciences Poster Day, Faculty of Medicine, Health Sciences Centre Kuwait University, Kuwait, April 21, 2003
}

\section{Undergraduate Student Awards}

\section{1 \\ Psychological and Sociodemographic Correlates of Glycaemic Control in Patients with Type 2 Diabetes mellitus \\ T.M. Zaid, D.A. Al-Khdair, A.H. Al-Terkait, I. Jevremovic \\ Department of Community Medicine, Faculty of Medicine, Kuwait University}

Introduction and Objectives: Tight glycaemic control is the best known strategy for improving prognosis in diabetes mellitus, but it is difficult to achieve. It requires substantial behavioural adjustments and compliance with therapy. We hypothesize that personality may play a major role in the determination of how well patients achieve glycaemic control. The objective of this study was to assess glycaemic control in type 2 diabetic patients and its relationship with personality. Sociodemographic indices were investigated for a possible confounding effect. Subjects and Methods: The study included 174 type 2 diabetic patients. A questionnaire was used to collect information on sociodemographic indices, disease profile and to measure neuroticism $(\mathrm{N})$ and extraversion (E) using a shortened version Eysenck Personality Questionnaire (EPQ). Measurements of glycated haemoglobin (HbA1c) were used as an index of glycaemic control. Results: The mean $\mathrm{HbAlc}$ was $8.76 \%$ ( $\mathrm{SD} \pm 2.48)$. Age correlated inversely with metabolic control $(\mathrm{r}=-0.17, \mathrm{p}<0.05)$. Females had worse control than males $(p<0.05)$. Respondents with different personality types had significantly different levels of $\mathrm{HbA} 1 \mathrm{c}$ with $\mathrm{E}+\mathrm{N}+$ having the worst glycaemic control $(\mathrm{p}<0.01)$. N+ respondents had on average $16 \%$ higher levels of $\mathrm{HbA} 1 \mathrm{c}$ compared to $\mathrm{N}-$ individuals $(\mathrm{p}<0.001)$. Multivariate logistic regression revealed that only $\mathrm{N}$ scores had a significant relationship with $\mathrm{HbA1c}$ with $\mathrm{N}+$ respondents being 2 times more likely to have poor glycaemic control $(p<0.05)$. Conclusion: The results of this study strongly support the association of personality type with glycaemic control. Neuroticism was found to be a possible risk factor for poor glycaemic control, if the assumption is made that personality traits do not change. These observations have potential clinical application.

\section{Evaluation of Testing the Lipid Profile in Patients with Acute Myocardial Infarction}

\author{
A. Al-Aqeel, O.A. Mojiminiyi, R. Al-Dashti, M. Abu-Rezq \\ Department of Pathology, Faculty of Medicine, \\ Kuwait University
}

Introduction and Objectives: The study was designed to evaluate the American College of Cardiology and American Heart Association guidelines, which recommend blood lipid analysis within $24 \mathrm{~h}$ of the onset of chest pain. Subjects and Methods: The study population comprised 83 (77 males and 6 females) patients with MI whose lipid profiles were obtained within $24 \mathrm{~h}$ of the onset of chest pain. Twenty (24\%) of the patients were on treatment with a statin. Diagnosis of $\mathrm{MI}$ in all patients was based on positive serum cardiac makers (CK-MB and/or troponin I) as well as ECG changes. TC, HDL and TG were measured with the Beckman LX20 automated analyzer. LDL was calculated with the Friedewald formula. Results: Twenty-three (28\%) of patients had normal cardiac marker levels on admission but later developed increased serum markers and ECG

\begin{tabular}{ll}
\hline KARGER & ( ) 2003 S. Karger AG, Basel \\
Fax +4161306 1234 $3411-7571 / 03 / 0124-0277 \$ 19.50 / 0$ \\
$\begin{array}{l}\text { E-Mail karger@karger.ch } \\
\text { www.karger.com }\end{array}$ & $\begin{array}{l}\text { Accessible online at: } \\
\text { www.karger.com/mpp }\end{array}$
\end{tabular}


changes of acute MI. Mean ( $95 \%$ CI) TC, HDL, TG, and LDL were $5.1(4.8-5.4) \mathrm{mmol} / \mathrm{l}, 0.93(0.88-0.98) \mathrm{mmol} / \mathrm{l}, 1.85$ (1.56-2.14) $\mathrm{mmol} / \mathrm{l}$, and $3.39(3.13-3.65) \mathrm{mmol} / \mathrm{l}$ respectively. Thirty-eight $(46 \%)$ of the patients had low HDL $(<0.9)$ and only $22(27 \%)$ patients met the National Cholesterol Education Program guidelines of target LDL $<2.6 \mathrm{mmol} / \mathrm{l}$. Conclusion: Primary prevention strategies should focus on treatment modalities that increase HDL. We recommend that the lipid profile should be done within $24 \mathrm{~h}$ of admission and lipid-lowering therapy initiated as part of secondary prevention strategy.

\section{Postgraduate Student Awards}

\author{
1 \\ The Association between Angiotensin I \\ Converting Enzyme Gene Polymorphism and \\ Microalbuminuria in Kuwaiti Type 2 Diabetic \\ Patients \\ D. Al-Khrayef, O.A. Mojiminiyi, F. Al-Mulla, N. Abdella, \\ V. Govindarajulu \\ Department of Pathology, Faculty of Medicine, \\ Kuwait University
}

Introduction and Objective: Studies of familial clustering and genetic predisposition suggest that genetic factors are involved in the pathogenesis of diabetic nephropathy. The angiotensin I converting enzyme (ACEI) is one candidate gene that may be associated with diabetic nephropathy in type 2 diabetic patients. The objective of this study was to investigate whether or not an association exists between ACEI gene polymorphism and diabetic nephropathy in type 2 Kuwaiti diabetics. Materials and Methods: I/D polymorphism, circulating ACE concentrations were determined by PCR and ACE ELISA, respectively, while nephropathy status was determined according to albumin/creatinine ratio $(\mu \mathrm{g} / \mathrm{mg})(<30$ normoalbuminuria, 30-300 microalbuminuria, $>300$ macroalbuminuria). Patients and controls were classified according to the insertion and deletion polymorphism of the ACEI gene as DD, ID and II. Results: The distribution of the genotypes in patients was not significantly different from controls in the Kuwaiti population - DD genotype: 50.4 vs. $54 \%$; ID genotype 28 vs. $30 \%$; II genotype 21.6 vs. $16 \%$. Patients and controls with DD genotype have higher ACEI plasma concentrations than those with ID, while those with II had lower values. Patients with microalbuminuria and macroalbuminuria tended to have high plasma ACEI concentration and a D allele in comparison with other groups $(p<0.001)$. Conclusions: Circulating ACEI is highly genetically determined. Diabetic patients with DD genotype have higher ACEI plasma concentrations and are likely to develop diabetic nephropathy. There is therefore an association between ACEI polymorphism and nephropathy in Kuwaiti patients with type 2 diabetes.

Funded by College of Graduate Studies, Kuwait University, Kuwait.

\section{2 \\ BRCA1 Gene Expression in Breast Cancer in Kuwait}

M. Amirrad, J.T. Anim, F. Al-Mulla, G. Varadharaj, S.S. George, N. Akhter

Department of Pathology, Faculty of Medicine, Kuwait University

Introduction and Objectives: Epidemiological studies in the Kuwaiti population show that breast cancer is the most common cancer in Kuwaiti women. BRCAl gene plays a critical role in both familial and sporadic types of breast cancer. In the absence of reliable data on familial breast cancer in Kuwait, a study of BRCA1 gene expression should assist in defining a subgroup that would contain familial forms of the disease. Worldwide, no study has analyzed the $B R C A 1$ gene expression at both mRNA and protein level. This study has been designed to determine if there is any reduction in BRCAl gene expression in breast cancer patients in Kuwait, and to determine if these data would be of use in segregating a subgroup containing familial breast cancer that can be further characterized by other studies. Materials and Methods: Random samples of archival paraffin-embedded breast cancer tissues from Mubarak Al-Kabeer Hospital, Kuwait, were studied for $B R C A 1$ gene expression. $B R C A 1$ protein expression was studied by an immunohistochemical method utilizing antibodies against different epitopes on $B R C A 1$ protein. A molecular technique, real-time RT-PCR, was used to detect $B R C A 1$ expression at mRNA level. Results: A significant reduction in $B R C A 1 \mathrm{mRNA}$ and protein expression was found in the majority of breast cancers studied. An inverse relationship was demonstrated between BRCA1 (mRNA and protein) expression and histological grade of breast cancer. Also, negative $B R C A 1$ (mRNA and protein) expression correlated with negative oestrogen and progesterone receptor status of the breast cancers, but increased expression of $C$ erbB-2. These findings confirm the inverse relationship between $B R C A 1$ expression and parameters that determine poor prognosis in breast cancer. Conclusion: The breast cancer patients, who had no $B R C A 1$ expression (both mRNA and protein), may be further investigated to ascertain a possible genetic basis for their cancer. Segregating breast cancer patients in Kuwait will be of special help for the family members of such patients, who can have the opportunity of $B R C A 1$ screening tests and the advantage of prophylactic management. This will open the way for future studies into the biology of breast cancer in this region.

Funded by College of Graduate Studies, Kuwait University. 


\section{Resident Award}

\section{1 \\ Serum Chromogranin A Levels in Healthy Kuwaitis and in Patients with Prostate Cancer}

A.K. Al-Anjary a, O.A. Mojiminiyia, E.O. Kehinde b, Y. Ali ${ }^{\text {b }}$, S. George ${ }^{\mathrm{a}}, \mathrm{R}$. Varghese ${ }^{\mathrm{b}}$

Departments of a Pathology and ${ }^{b}$ Surgery, Mubarak Al-Kabeer Hospital and Faculty of Medicine, Kuwait University, Kuwait

Introduction and Objectives: The search is still on for the ideal tumour marker for the evaluation of patients with a clinical suspicion of prostate cancer (PC). We examined whether or not serum chromogranin $\mathrm{A}(\mathrm{CgA})$ enhances the power of serology in assessing PC. We also aimed to establish the reference range for $\mathrm{CgA}$ in Kuwaitis. Subjects and Methods: We studied 37 PC patients, 44 healthy Kuwaiti males and 32 healthy Kuwaiti females. Serum $\mathrm{CgA}$ levels were determined by ELISA using DAKO CgA ELISA kits. Results: The mean $\mathrm{CgA}$ concentration was significantly higher in PC patients (108.4 U/l) than in healthy males as shown in the table below. The mean $\mathrm{CgA}$ concentration was higher in healthy males than in healthy females. In the healthy groups, $\mathrm{CgA}$ levels were highest in the older males (age group 70-79 years).

\begin{tabular}{llccc}
\hline \multirow{2}{*}{$\begin{array}{l}\text { Age } \\
\text { years }\end{array}$} & \multicolumn{4}{l}{ Mean CgA level, U/l } \\
\cline { 2 - 5 } & males & $\mathrm{n}$ & females & $\mathrm{n}$ \\
\hline $15-19$ & 11.0 & 6 & 17.0 & 1 \\
$20-29$ & 39.3 & 6 & 26.8 & 8 \\
$30-39$ & 31.2 & 5 & 46.9 & 8 \\
$40-49$ & 16.0 & 10 & 29.2 & 8 \\
$50-59$ & 16.0 & 6 & 17.2 & 7 \\
$60-69$ & 36.3 & 6 & - & - \\
$70-79$ & 80.6 & 4 & - & - \\
Mean & 32.9 & 43 & 27.4 & 36 \\
\hline
\end{tabular}

$\mathrm{n}=$ Number of subjects.

Conclusion: The mean serum $\mathrm{CgA}$ is higher in healthy males than in healthy females, and also in patients with prostate cancer where it may have a diagnostic utility.

\section{Basic and Applied Sciences Awards}

\section{1 \\ CFTR Gene Mutation Analysis in Cystic Fibrosis Patients from Kuwait}

\section{E. Samilchuk, S. Al-Awadi}

Kuwait Medical Genetics Centre, Kuwait

Introduction and Objectives: Cystic fibrosis (CF), one of the most common single gene disorders, is caused by mutations in the CFTR gene. Of the more than 1,000 CFTR mutations reported, most are very rare or even confined to a single family. There is significant ethnic variability in the distribution of CFTR mutations. Little is known about the mutations in patients with $\mathrm{CF}$ residing in Kuwait and the aim of this study was to identify these mutations. Subjects and Methods: DNA samples were collected from 25 unrelated CF families of different ethnic origin residing in Kuwait (Kuwaiti, Omani, Saudi, Syrian, Pakistani, Iranian, Indian, Bedouin). Most of the families were consanguineous. The major techniques used were polymerase chain reaction (PCR), restriction fragment length polymorphism (RFLP), heteroduplex analysis, and DNA sequencing. Results: Eight CFTR mutations, including one novel mutation (C128R), were identified in 31 of $50(62 \%) \mathrm{CF}$ chromosomes. The mutation frequencies were as follows: deltaF508 - 8/50 (16\%), W1282X - 5/50 (10\%), I1234V - 4/50 (8\%), 1548delG - 4/50 (8\%), $\mathrm{S} 549 \mathrm{~N}-4 / 50(8 \%), 3120+1 \mathrm{~g} \rightarrow \mathrm{a}-2 / 50(4 \%)$, I560T $-2 / 50(4 \%)$, and C128R - 2/50 (4\%) of CF chromosomes. In 38\% of CF chromosomes mutations were not identified. The Kuwaiti patients had 5 mutations (deltaF508, W1282X, I1234V, 1548delG, 3120 + 1g $\rightarrow$ a). The common S549N mutation was observed in two Pakistani families. A very rare I506T mutation was detected in an Iranian patient. The novel C128R mutation (cysteine replaced by arginine) is a single nucleotide substitution $(514 \mathrm{~T} \rightarrow \mathrm{C})$ in exon 4 . It was identified in the Pakistani patient with a very severe clinical phenotype. Conclusion: The results of our study provide opportunity for carrier detection, prenatal, and pre-implantation diagnosis in CF families with known mutations. At the same time, efforts to identify mutations underlying $\mathrm{CF}$ in the region should be continued.

\section{2 \\ Overexpression of Wild-Type p53 Gene Renders MCF-7 Breast Cancer Cells More Sensitive to the Anti-Proliferative Effect of Progesterone}

M. Al-Khalaf, A. El-Mowafy, M. Bakir, L. Verghese

Department of Biochemistry, Faculty of Medicine and Department of Applied Therapeutics, Faculty of Pharmacy, Kuwait University

Introduction and Objectives: We have recently shown that growth inhibition of breast cancer cells by progesterone is due to the induction of cell differentiation, but not apoptosis. The aim of this 
work was to examine the involvement of altered expression of the tumour suppressor protein $\mathrm{p} 53$ in progesterone-induced inhibition of human breast cancer growth. Materials and Methods: Western blot analysis was used to analyze the endogenous levels of p53 in MCF7 breast cancer cells treated with progesterone. To study the effect of progesterone on cell growth in the presence of normal levels of $\mathrm{p} 53$ protein, we used transient transfection to overexpress p 53 protein. MCF-7 cells were transfected with a P53-expressing vector that contains p53 human cDNA under the control of a cytomegalovirus promoter. Cell growth, cell viability and apoptosis were analyzed in the transfected cells after 6 days of exposure to $100 \mathrm{n} M$ progesterone. Results: The anti-proliferative effect of progesterone was accompanied by down-regulation of endogenous $\mathrm{p} 53$ protein. When $\mathrm{p} 53$ levels were increased by transfection, progesterone significantly enhanced growth inhibition and apoptosis in MCF-7 cells overexpressing P53 but not in cells transfected with the control vector. Conclusion: Altered expression of p53 in human breast cancer cells can alter proliferative responsiveness to progesterone and suggest that such a mechanism may be associated with resistance to progestin therapy of human breast cancer. Therefore, re-establishing $\mathrm{p} 53$ function in breast tumours is necessary to enhance responsiveness to progestin therapy of breast cancer.

Funded by Kuwait University Grant No. MB 028.

\section{3 \\ Substance P Employs Multiple Intermediate Neuromodulators to Depress Excitatory Synaptic Transmission in the Rat Nucleus accumbens in vitro \\ S.B. Kombian, K.V.V. Ananthalakshmi, S.S. Parvathy, W.C. Matowe \\ Departments of Applied Therapeutics \& Pharmacy Practice, Faculty of Pharmacy, Kuwait University}

Introduction and Objective: The nucleus accumbens (NAc) is a forebrain structure that is part of the neural circuit, which mediates complex emotions including drug-seeking behaviour. Biochemical and behavioural studies implicate dopamine (DA) in these behaviours. Similar studies indicate that some peptides present in the NAc mimic the actions of dopamine while others antagonize them. The cellular mechanism(s) by which one such peptide, Substance P (SP), may alter NAc function is not known. We tested the hypothesis that SP would depress excitatory synaptic transmission in the NAc. Materials and Methods: Para-sagittal forebrain slices containing the NAc were generated from male Sprague-Dawley rats. Whole cell and nystatin-perforated patch recording techniques were employed and evoked excitatory postsynaptic currents/potentials were recorded in voltage and current clamp modes respectively. Results: Bath application of SP caused a partially reversible, dose-dependent decrease in pure evoked EPSCs. Maximum EPSC depression (41.5 $\pm 3.6 \%, \mathrm{n}=6$ ) was at $1 \mu M \mathrm{SP}$ with higher doses causing less depression. This synaptic depression was mimicked by [Sar9, Met (O2)11]$\mathrm{SP}(1 \mu M, 42.7 \pm 2.5 \%, \mathrm{n}=4)$, a selective neurokinin 1 (NK1) receptor agonist and blocked by $10 \mu M \mathrm{~L} 732138$, a NK1 receptor-selective antagonist $(2.8 \pm 5.1 \%, \mathrm{n}=4, \mathrm{p}>0.05)$. The SP and [Sar9, Met
(O2)11]-SP-induced synaptic depression was accompanied by increases in PPF but no changes in holding current, input resistance and steady-state I-V curves. The SP-induced synaptic depression was blocked by the DA receptor antagonists haloperidol (50 $\mu M, 12.9 \pm$ $6.2, \mathrm{n}=4, \mathrm{p}>0.05)$ and a combination of SCH23390 $(30 \mu M)$ and sulpiride $(10 \mu M, 8.5 \pm 5.5, \mathrm{n}=4, \mathrm{p}>0.05)$. The adenosine A1 receptor antagonist, 8-cyclopentyltheophylline $(1 \mu M)$ also blocked the SP-induced synaptic depression $(1.6 \pm 1.5 \%, \mathrm{n}=6, \mathrm{p}>0.05)$. Conclusion: These results indicate that SP depresses excitatory synaptic transmission in the NAc through pre-synaptic mechanisms utilizing dopamine and adenosine as mediators.

Funded by Kuwait Foundation for Advancement of Sciences Grant (KFAS) \# 98-07-09.

\section{Clinical Sciences Awards}

\section{1 Human Chromogranin A in Patients with
Hyperthyroidism}

K.A.S. Al-Shoumer, B.K. Vasanthy, M.M. Al-Zaid

Division of Endocrinology \& Metabolic Medicine, Department of Medicine, Faculty of Medicine, Kuwait University and Ministry of Health, Kuwait

Introduction and Objectives: Human chromogranin A ( $\mathrm{CgA})$ is an acidic glycoprotein co-released with catecholamines. It has been used as a sensitive marker for neuroendocrine tumours, but its secretion in patients with hyperthyroidism (where the basal metabolic rate is raised) has not been evaluated. The aim of this study was to assess the level of $\mathrm{CgA}$ in patients with hyperthyroidism compared to control subjects. Subjects and Methods: $\mathrm{CgA}$ levels were measured by ELISA in 29 hyperthyroid (Graves' disease) patients and in 32 controls. Both groups of subjects were matched for age (patients vs. controls, mean \pm SEM, $34 \pm 1$ vs. $34 \pm 2$ years), sex and body mass index $\left(22.5 \pm 0.8\right.$ vs. $\left.23.8 \pm 0.7 \mathrm{~kg} / \mathrm{m}^{2}\right)$. All subjects were initially studied after $12 \mathrm{~h}$ of overnight fasting; the hyperthyroid patients were then studied again, 6 months later, after they had been rendered euthyroid with antithyroid drugs (carbimazole only). Results: Untreated patients with Graves' disease had significantly higher CgA $(93.4 \pm 28.7$ vs. $19.0 \pm 8.6 \mathrm{U} / 1, \mathrm{p}=0.024)$ than controls. In the patients, $\mathrm{CgA}$ levels dropped significantly after therapy with antithyroid drugs $(37.4 \pm 11.5 \mathrm{U} / 1, \mathrm{p}=0.023$ compared with pre-treatment level) to similar values as controls. CgA levels in subjects demonstrated a strong positive correlation with free $\mathrm{T}_{3}(\mathrm{r}=0.66, \mathrm{p}=0.026)$ but not with free $\mathrm{T}_{4}$ or TSH. Conclusions: $\mathrm{CgA}$ level is elevated in untreated hyperthyroidism due to Graves' disease. Treatment with antithyroid drugs had normalized its level in 6 months. $\mathrm{CgA}$ is useful as a potential marker for thyroid hyperactivity. 
2

The Safety and Clinical Efficacy of Subcutaneous

Specific Immunotherapy with Pollen Allergen Extracts for Respiratory Allergy

N. Arifhodzic, N. Behbehani, A.R. Dowaisan, M. Al-Mosawi, M. Khan

Al-Rashed Allergy Centre and Department of Medicine,

Faculty of Medicine, Kuwait University, Kuwait

Introduction and Objectives: Specific immunotherapy (SIT) represents the only specific treatment that may change the natural course of allergic disorders. However, this mode of treatment is still controversial and associated with the risk of systemic reactions. The aim of this study was to evaluate safety and efficacy of SIT given by subcutaneous route for 3 years to patients with seasonal allergic rhinitis (AR) with or without asthma. Subjects and Methods: The prospective open label study was conducted at the Al-Rashed Allergy Centre, Kuwait. Inclusion criteria were: age 15-40 years, diagnosis of either AR or AR with asthma for 2 or more consecutive years, sensitization to one or more local pollen allergens and poor control of symptoms with pharmacotherapy. Exclusion criteria were: prior SIT treatment or severe asthma. The allergen extracts used were a modified aluminium depot of Chenopodium album, Bermuda grass, or both. After an initial dose-escalation phase, a maintenance dose of $0.5 \mathrm{ml}$ of $100,000 \mathrm{PNU} / \mathrm{ml}$ was administered monthly for 3 years. The occurrence and severity of systemic (SR) and local reactions was recorded and graded according to the WHO position paper. The clinical efficacy was assessed by symptom score, change in medication, patient's subjective assessment of therapeutic benefit, change in skin prick test (SPT) and specific IgE measurement. Results: There were 181 patients enrolled in the study but 57 (31\%) did not complete it (53 due to poor compliance and 4 due to systemic side effects). All 4 patients who developed SR had asthma and all the SR occurred during the dose-escalation phase. In 1 case, SR occurred at the concentration of 100,000 PNU/ml (4th concentration), while in 3 cases it happened at the concentration of $10,000 \mathrm{PNU} / \mathrm{ml}$ (3rd concentration). Three patients had moderate systemic reaction (grade 2) while 1 had severe reaction (grade 3). Three of the SR occurred within the first $20 \mathrm{~min}$ after injection and 1 occurred $2 \mathrm{~h}$ after injection. None of the reactions was life-threatening and all were managed easily. Significant local reaction (erythema $>5 \mathrm{~cm}$ in the first $6 \mathrm{~h}$ ) occurred in 43 $(8.3 \%)$ patients. None of the patients who had SR had prior local reaction. Total symptom score decreased from $11.8 \mathrm{~mm}$ at baseline to $7.46 \mathrm{~mm}$ at the end of treatment $(\mathrm{p}<0.001)$. At the end of the study, $9(7 \%)$ patients were not using any medications, while 109 $(88 \%)$ patients had reduced their medication. The size of SPT reac- tion to the main sensitizing allergen reduced from $7.48 \pm 2.26 \mathrm{~mm}$ at baseline to $5.60 \pm 2.18 \mathrm{~mm}$ at end of treatment $(\mathrm{p}<001)$. Conclusion: If a strict protocol is used, SIT is safe and effective in AR patients with or without mild asthma. The rate of systemic reaction is low with no associated mortality. Asthma is a risk factor for development of SR and local reaction was not a predictor for development of SR

\section{3 \\ Relationships of the Serum Concentration of Interleukin-18 to the Biochemical Features of the Metabolic Syndrome}

S.O. Olusi, M. Abraham, S. George, R. Mathew

Department of Pathology, Faculty of Medicine, Kuwait University

Introduction and Objectives: Recently, we reported that the serum concentration of IL-18 is up-regulated in obesity and that it is related to increased lipid peroxidation in this condition. Since obesity is one of the features of the metabolic syndrome, we postulated that this cytokine might be involved in this syndrome. The aim of this study, therefore, was to find out if there was an association between the serum concentration of IL-18 and some of the metabolic features of Syndrome X. Subjects and Methods: The study population consisted of 570 apparently healthy adults whose weight and height were recorded. 12-hour fasting serum concentrations of glucose, total cholesterol (TC), triglyceride (TG), high-density lipoprotein cholesterol (HDL-C) and uric acid were measured on a chemistry analyzer. Serum IL-18 was estimated in the samples using commercially available ELISA kits. Partial correlation and univariate regression analyses were used to assess the relationships of serum IL18 with age, sex, BMI, serum glucose, lipids and uric acid. Results: Univariate regression analysis showed that serum concentration of IL-18 was positively related to age $(\mathrm{r}=0.30, \mathrm{p}=0.001)$, BMI $(\mathrm{r}=$ $0.27, p=0.01)$ TC $(r=0.22, p=0.03), T G(r=0.38, p=0.001)$, fasting serum glucose $(r=0.29, p=0.01)$ and uric acid $(r=0.18, p=$ $0.06)$ in the total population. After controlling for age, sex and BMI, serum IL-18 remained robustly associated with TG $(\mathrm{r}=0.36, \mathrm{p}=$ $0.001)$, glucose $(r=0.39, p=0.001)$ and uric acid $(r=0.36, p=0.001)$. Conclusion: It is concluded that serum IL-18 concentration is associated with some of the features of the metabolic syndrome and may therefore be important in the pathogenesis of this syndrome. 